\title{
PENGARUH CURRENT RATIO (CR) DAN TOTAL ASSETS TURN OVER (TATO) TERHADAP RETURN ON EQUITY (ROE) PADA PT PERTAMINA (PERSERO) PERIODE 2010-2019
}

\author{
${ }^{1 *}$ Yulian Bayu Ganar, 2 Rosmana Yanti \\ Universitas Pamulang, Tangerang Selatan, Banten, Indonesia \\ *dosen01534@unpam.ac.id
}

\begin{abstract}
Abstrak
Penelitian ini bertujuan untuk mengetahui pengaruh Current Ratio (CR) terhadap Return On Equity (ROE) pada PT. Pertamina (Persero). Baik secara parsial maupun simultan. Jenis penelitian yang digunakan adalah kuantitatif. Sampel yang digunakan dalam penelitian ini yaitu laporan keuangan yang berupa neraca dan laporan laba rugi periode 2010 - 2019 pada PT. Pertamina (Persero). Tekhnik analisis menggunakan analisis regresi linier berganda, uji hipotesis menggunakan uji t pengujian koefisien regresi parsial dan uji f untuk menguji koefisien regresi simultan dengan level of significance $5 \%$.Dari pengujian signifikansi uji t secara parsial, Current Ratio (CR) tidak terdapat pengaruh positif signifikan terhadap Return On Equity (ROE) dengan hasil uji nilai thitung lebih kecil dari pada ttabel $(1,430<2,30600)$ dan nilai signifikansi lebih besar dari 0,05 yaitu 0,196 $(0,196>0,05)$. Total Assets Turn Over (TATO) terdapat pengaruh positif signifikan dengan hasil uji thitung lebih besar dari pada ttabel $(2,790>2,30600)$ dan nilai sigifikan lebih kecil dari 0,05 yaitu 0,030 $(0,030<0,05)$. Secara simultan terdapat pengaruh yang signifikan antara Current Ratio (CR) dan Total Assets Turn Over (TATO) terhadap Return On Equity (ROE).

Kata Kunci: CR, TATO, ROE
\end{abstract}

\section{Abstract}

This study aims to determine the effect of Current Ratio (CR) on Return On Equity (ROE) at PT. Pertamina (Persero). Either partially or simultaneously. The type of research used is quantitative. The sample used in this study is the financial report in the form of a balance sheet and income statement for the period 2010 - 2019 at PT. Pertamina (Persero). The analysis technique uses multiple linear regression analysis, hypothesis testing using $t$-test partial regression coefficient testing and f-test to test simultaneous regression coefficients with a significance level of $5 \%$ on Return On Equity (ROE) with test results tcount value is smaller than ttable (1.430 $<2.30600)$ and the significance value is greater than 0.05, namely $0.196(0.196>0.05)$. Total Assets Turn Over (TATO) has a significant positive effect with $t$-test results greater than $t$-table $(2.790>2.30600)$ and a significant value less than 0.05 , namely $0.030(0.030<0.05)$. Simultaneously there is a significant effect between Current Ratio (CR) and Total Assets Turn Over (TATO) on Return On Equity (ROE).

Keywords: CR, TATO, ROE

\section{PENDAHULUAN}

Perkembangan di bidang ilmu dan teknologi telah mencapai kemajuan yang sangat pesat, sehingga mempengaruhi pula perkembangan di dunia usaha, hal ini mengakibatkan persaingan yang sangat ketat di dalam bisnis antara satu perusahaan dengan perusahaan lainnya baik perusahaan milik swasta atau perusahaan milik negara. Pada umumnya tujuan dari sebuah perusahaan adalah mencapai profit yang maksimal dalam menjalankan usahanya. Maka dari itu salah satu cara yang dilakukan untuk mengetahui kondisi keuangan perusahaan yaitu dengan menginterprestasikan atau menganalisis keuangan, yang bertujuan untuk mengetahui keadaan dan perkembangan keuangan dari tahun ke tahun pada perusahaan yang bersangkutan. Hasil ini dapat digunakan pemilik perusahaan atau manajer perusahaan untuk perbaikan penyusunan rencana yang akan dilakukan di waktu yang akan datang. Mengetahui 
kelemahan-kelemahan laporan keuangan dapat diperbaiki dengan hasil yang cukup baik dapat dipertahankan di waktu yan akan datang.

PT. Pertamina (Persero) adalah perusahaan yang dimilki pemerintah Indonesia (National Oil Company) yaitu sebuah BUMN yang bertugas mengelola penambnagan minyak dan gas bumi di indonesia. Pertamina masuk urutan ke 122 dalam Fortune Global 500 pada tahun 2013. Pertamina pernah mempunyai monopoli pendirian SPBU di indonesia, namun monopoli tersebut telah di hapuskan pemerintah pada tahun 2001. Perusahaan ini juga mengoperasikan 7 kilang minyak dengan kapasitas total 1.051,7 MBSD, pabrik petrokimia dengan kapasitas total 1.507.950 ton per tahun dan pabik LPG dengan kapasitas total 102,3 juta ton per tahun. Pertamina adalah hasil gabungan dari perusahaan pertamina dengan permina yang didirikan pada tanggal 10 Desember 1957.

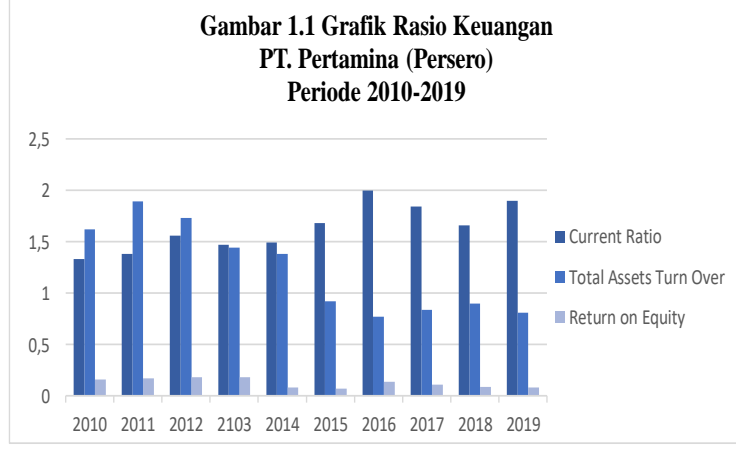
Sumber : Data diolah

Berdasarkan grafik di atas dapat disimpulkan bahwa Current Ratio (CR), Total Assets Turn Over (TATO) maupun Return on Equity (ROE) pada PT. Pertamina (Persero) mengalami berfluktuatif. Hal tersebut diduga adanya pengaruh Current Ratio dan Total Assets Turn Over terhadap Return On Equity. Motivasi dalam melakukan penelitian ini adalah untuk menguji ada atau tidaknya pengaruh Current Ratio (CR) dan Total Assets Turn Over (TATO) berdasarkan data akuntansi pada perusahaan terhadap profitabilitas dengan menggunakan Return on Equity (ROE) sebagai variabel dependen.

\section{TINJAUAN PUSTAKA}

\section{Rasio Lancar (Current Ratio)}

Menurut Kasmir (2015) Rasio lancar merupakan rasio untuk mengukur kemampuan perusahaan dalam membayar kewajiban jangka pendek atau utang yang segera jatuh tempo pada saat ditagih secara keseluruhan. Perhitungan rasio lancar dilakukan dengan cara membandingkan antara total aktiva lancar dengan total utang lancar. Aktiva lancar (Current Assets) merupakan harta perusahaan yang dapat dijadikan uang dalam waktu singkat. Menurut Kasmir (2015) rumus untuk menghitung hasil current ratio dapat menggunakan rumus:

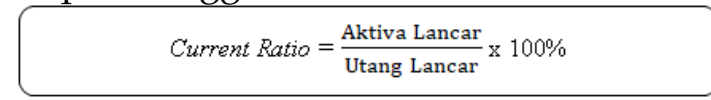

2. Total Assets Turn Over (Perputaran Aktiva)

Merupakan rasio perbandingan antara penjualan dengan total aktiva suatu perusahaan yang menjelaskan tentang kecepatan perputaran total aktiva dalam suatu periode tertentu. Rumus untuk mencari Total Assets Turn Over yaitu:

$$
\text { Total Assets Turn Over }=\frac{\text { Penjualan }}{\text { Total Aktiva }} \times 100 \%
$$

\section{Return on Equity (ROE)}

Return On Equity merupakan rasio untuk mengukur laba bersih sesudah pajak dengan modal sendiri. Rasio ini menunjukan efesiensi penggunaan modal sendiri. Semakin tinggi rasio, semakin baik. Rumus untuk mencari Return On Equity, yaitu:

Return On Equity $=\frac{\text { Laba Bersih Setelah Pajak }}{\text { Total Ekuitas }} \times 100 \%$

\section{METODE}

Populasi dalam penelitian ini merupakan keseluruhan Laporan Keuangan PT. Pertamina (Persero). Sampel merupakan sebagian atau wakil populasi yang diteliti. Dalam penelitian ini adalah laporan rugi laba dan neraca PT. Pertamina (Persero) 
Jenis penelitian ini bersifat deskriptif kuantitaif, yaitu suatu bentuk penelitian yang berdasarkan data yang dikumpulkan selama penelitian secara sistematik mengenai fakta-fakta dan sifat-sifat dari objek yang diteliti dengan menggabungkan hubungan antara variabel yang ada didalmnya, kemudian diinterprestasikan berdasarkan teori yang berhubungan.. Dalam menganalisis data digunakan uji validitas, uji reliabilitas, analisis regresi linier sederhana, analisis koefisien korelasi, analisis koefisien determinasi dan pengujian hipotesis.

\section{HASIL DAN PEMBAHASAN}

\section{Analisis Deskriptif}

Pada pengujian ini digunakan untuk mengetahui nilai minimum dan maksimum nilai tertinggi, ratting score dan standar deviasi dari masing-masing variabel. Adapun hasilnya sebagai berikut:

Tabel 1. Hasil Analisis Descriptive Statistics

\begin{tabular}{|l|r|r|r|r|r|}
\hline \multicolumn{6}{|c|}{ Descriptive Statistics } \\
\hline & $\mathrm{N}$ & Minimum & Maximum & Mean & Std. Deviation \\
\hline Current Ratio & 10 & 1.33 & 2.00 & 1.6310 & .22605 \\
Total Assets Turn Over & 10 & .77 & 1.89 & 1.2300 & .42810 \\
Return On Equity & 10 & .07 & .18 & .1260 & .04477 \\
Valid N (listwise) & 10 & & & & \\
\hline
\end{tabular}

Dari data tabel diatas dijelaskan bahwa variabel dependen $(\mathrm{Y})$ dengan jumlah data sebanayak 10 data. Adapun statistik deskriptif yang telah diolah sebagai berikut:

Variabel Current Ratio memiliki nilai minimum sebesar 1,33 pada tahun 2010, maximum sebesar 2,00 pada tahun 2016 dari nilai mean sebesar 1,6310 dengan nilai standar deviasi sebesar 0,22605 .

Variabel Total Assets Turn Over memiliki nilai minimum sebesar 0,77 pada tahun 2016 dan nilai maximum sebesar 1,89 pada tahun 2011 dari nilai mean sebesar 1,2300 dengan nilai standar deviasi sebesar 0,42810.

Variabel Return On Equity memiliki nilai minimu sebesar 0,07 pada tahun 2015 dan nilai maksimum sebesar 0,18 pada tahun 2012 dan 2013 dari nilai mean sebesar 0,1260 dengan nilai standar deviasi sebesar 0,4477.

\section{Analisis Regresi Linier Berganda.}

Analisis regresi ini digunakan untuk mengetahui seberapa besar pengaruh variabel independen terhadap variabel dependen yaitu Current Ratio dan Total Assets Turn Over terhadap profitabilitas (Return On Equity) PT. Pertamina (Persero) persamaan regresi yang digunakan adalah:

$$
\mathrm{Y}=\mathrm{a}+\mathrm{b} \mathbf{1} \mathbf{X 1}+\mathrm{b} 2 \mathrm{X} \mathbf{2}
$$

Adapun perhitungan regresi linear berganda dibantu dengan menggunakan sistem SPSS dari data yang telah dianalisis adalah sebagai berikut:

Tabel 2. Hasil Pengujian Regresi Linier Berganda

\begin{tabular}{|c|c|c|c|c|c|c|}
\hline \multicolumn{7}{|c|}{ Coefficients $^{a}$} \\
\hline \multirow{2}{*}{\multicolumn{2}{|c|}{ Model }} & \multicolumn{2}{|c|}{ Unstandardized Coefficients } & Standardized Coefficients & \multirow[b]{2}{*}{$\mathrm{t}$} & \multirow[b]{2}{*}{ Sig. } \\
\hline & & B & Std. Error & Beta & & \\
\hline \multirow[t]{3}{*}{1} & (Constant) & -.268 & .214 & \multirow{3}{*}{$\begin{array}{r}.695 \\
1.316\end{array}$} & -1.251 & .251 \\
\hline & Current Ratio & .138 & .096 & & 1.430 & .196 \\
\hline & Total Assets Turn Over & .138 & .051 & & 2.709 & .030 \\
\hline
\end{tabular}

Berdasarkan hasil pengujian pada tabel di atas, diperoleh persamaan regresi Return On Equity $(\mathrm{Y})=-0,268$
Constant + 0,138X1 + 0,138X2. Dari persamaan tersebut dijelaskan sebagai berikut: 
a. Konstanta (a) menunjukan bahwa persamaan regresi linier berganda yaitu sebesar -1,268 menyatakan bahwa jikai nilai Current Ratio dan Total Assets Turn Over adalah nol, maka konstanta hasil Return On Equity yang terjadi adalah sebesar 0,268 .

b. Nilai Current Ratio menunjukan nilai 0,138 dengan koefisien positif yang artinya setiap Current Ratio meningkat satu satuan, maka Return On Equity akan mengalami kenaikan sebesar 0,138 satuan dengan berasumsi bahwa variabel bebas yang lain dianggap konstan.

c. Nilai Total Assets Turn Over menunjukan nilai 0,138 dengan koefisien positif yang artinya setiap Total Assets Turn Over meningkat satu satuan, maka Return On Equity akan mengalami peningkatan sebesar 0,138 dengan berasumsi bahwa variabel bebas yang lain dianggap konstan.

\section{Analisis Koefisien Determinasi}

Koefisien determinasi (R2) pada intinya mengukur seberapa jauh kemampuan model dalam menerangkan variasi variabel dependen. Nilai koefisien determinasi dapat diukur oleh nilai R Square atau Adjusted R Square. R Square digunakan pada saat variabel bebas hanya 1 (satu) saja, sedangkan Adjusted R Square digunakan pada saat variabel lebih dari satu. Hasil uji koefisien determinasi antara Current Ratio, Total Assets Turn Over terhadap Return On Equity dapat dilihat pada tabel berikut:

Tabel 3. Hasil Pengujian Koefisien Determinasi

\begin{tabular}{|l|c|r|r|r|}
\hline \multicolumn{5}{|c|}{ Model Summary } \\
\hline Model & $\mathrm{R}$ & R Square & Adjusted R Square & Std. Error of the Estimate \\
\hline 1 & $.784 \mathrm{a}$ & .614 & .504 & .03155 \\
\hline $\begin{array}{l}\text { a. Predictors: (Constant), Total Assets Turn Over, Current Ratio } \\
\text { b. Dependent Variable: Return On Equity }\end{array}$ \\
\hline
\end{tabular}

Tabel diatas menunjukan nilai $R$ Square sebesar 0,614 maka $(\mathrm{KD}=\mathrm{r} 2$ $\mathrm{x} 100 \%=0,614 \times 100 \%=61,4 \%)$, hal ini menandakan bahwa variabel Current Ratio, Total Assets Turn Over hanya dapat menjelaskan $61,4 \%$ variasi Return On Equity. Sedangkan sisanya yaitu $38,6 \%(100 \%-61,4 \%)$ dijelaskan oleh variabel -variabel lain yang belum diketahui atau diduga ada variabel lain yang mempengaruhi $\mathrm{Y}$ yang tidak digunakan dalam penelitian ini. Dengan melihat nilai standart error of the estimate yaitu sebesar 0,03155 .

\section{Uji Hipotesis \\ Uji $t$}

Pengujian hipotesis dengan uji $t$ digunakan untuk mengetahui hipotesis mana yang diterima antara variable independent terhadap dependen. berikut:

Tabel 4. Hasil Uji t

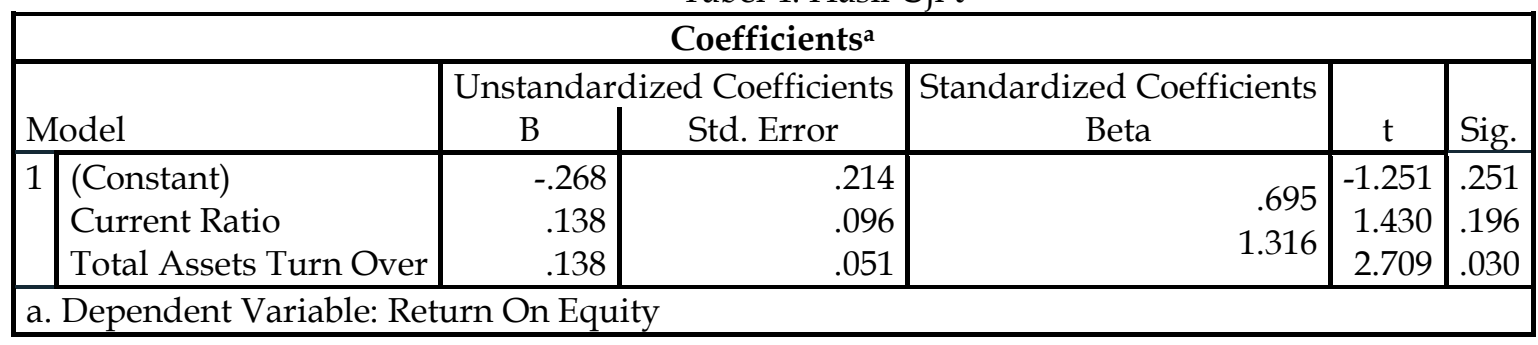


variabel X1 Current Ratio terhadap variabel Y Return On Equity maka diperoleh nilai thitung sebesar 1,430 dan dengan nilai signifikan sebesar 0,196 diatas 0,05 atau $(0,196>0,05)$, dejarat kebebasan $(\mathrm{dk})=10-2=8$ adalah sebesar 2,30600. Dengan melakukan perbandingan yaitu thitung $(1,430)<$ ttabel $(2,30600)$ sehingga dapat disimpulkan bahwa HO1 diterima dan Ha1 ditolak, maka tidak ada pengaruh yang signifikan secara parsial terhadap Return On Equity.

Variabel Total Assets Turn Over terhadap variabel Y Return On Equity maka diperoleh nilai thitung sebesar 2,709 dengan nilai signifikan 0,030, yang artinya angka ini lebih kecil dari tingkat signfikansi 0,05 atau $(0,030<0,05)$, derajat kebebasan $(\mathrm{dk})=10-2=8$ adalah sebesar 2,30600. Dengan melakukan perbandingan yaitu thitung $(2,709)>$ ttabel (2,30600) sehingga dapat disimpulkan bahwa H02 ditolak dan Ha2 diterima, maka terdapat pengaruh yang signifikan secara parsial terhadap Return On Equity.

\section{Uji F}

Uji f digunakan untuk menguji pengaruh independen yaitu Debt to Asset Ratio dan Current Ratio secara bersama-sama terhadap variabel Return On Equity yaitu dengan membandingkan antara nilai Fhitung dan F tabel. Berikut hasil pengujian uji $\mathrm{F}$ yang telah dilakukan:

Tabel 5. Hasil Uji F

\begin{tabular}{|l|r|r|r|r|c|c|}
\hline \multicolumn{7}{|c|}{ ANOVA $^{\text {a }}$} \\
\hline Model & Sum of Squares & df & Mean Square & F & Sig. \\
\hline 1 & Regression & .011 & 2 & .006 & 5.564 & $.036^{\mathrm{b}}$ \\
& Residual & .007 & 7 & .001 & & \\
\multicolumn{2}{|l|}{ Total } & .018 & 9 & & & \\
\hline
\end{tabular}

hasil pengujian Analysis Of Variance (ANOVA) diatas diperoleh nilai fhitung sebesar 5,56 dengan nilai signifikansi 0,036 yang artinya nilai signifikansi lebih kecil dari $\alpha=0,05(0,036$ $<0,05)$, sedangkan ftabel dengan signifikansi $5 \%$ dan df1 $=\mathrm{k}=2$, df2 $=10$ - $2=8$, diperoleh ftabel sebesar 4,46. Dengan kondisi ini dimana fhitung lebih besar dari pada ftabel $(5,56>4,46)$ maka dapat disimpulkan bahwa Ho ditolak, maka secara bersama-sama Current Ratio dan Total Assets Turn Over terdapat pengaruh signifikan terhadap variabel Return On Equity.

\section{PEMBAHASAN HASIL PENELITIAN}

1. Pengaruh Current Ratio terhadap Return On Equity

Secara parsial variabel Current Ratio terhadap Return On Equity tidak berpengaruh, dilihat dari hasil uji $t$ menunjukan Current Ratio nilai signifikan sebesar 0,196 yang artinya angka ini lebih besar dari tingkat signifikan 0,05 atau $(0,196>0,05)$. Sedangkan hasil uji thitung sebesar 1,430 menunjukan hasil lebih kecil dari pada ttabel 2,30600 atau $(1,430)<(2,30600)$.

2. Pengaruh Total Assets Turn Over terhadap Return On Equity

Dari hasil penelitian ini variabel Total Assets Turn Over secara parsial terdapat pengaruh terhadap Return On Equity, dilihat dari uji $t$ menunjukan Total Assets Turn Over nilai signifikan sebesar 0,030 yang artinya angka ini lebih kecil dari tingkat signifikan 0,05 atau $(0,030<0,05)$. Sedangkan hasil uji thitung sebesar 2,790 menunjukan hasil lebih besar dari ttabel sebesar 2,30600 atau $(2,790>2,30600)$. Hal ini menunjukan bahwa perusahaan baik dalam mengoptimalkan aset perusahaan. Hasil ini sejalan dengan penelitian Desi Kartikaningsih (2013) yang menyatakan 
bahwa Total Assets Turn Over berpengaruh positf secara parsial terhadap Return On Equty.

3. Pengaruh Current Ratio dan Total Assets Turn Over terhadap Return On Equity Secara simultan terdapat pengaruh positif signifikan antara Current Ratio dan Total Assets Turn Over terhadap Return On Equity. Hal ini dilihat dari nilai signifikan sebesar 0,036 sedangkan hasil uji fhitung sebesar 5,56 lebih besar dari ftabel sebesar 4,46 atau $(5,56>4,46)$. Dari hasil penelitian yang telah dilakukan menunjukan bahw Current Ratio dan Total Assets Turn Over berpengaruh secara simultan terhadap Return On Equity. Yang artinya karena nilai Current Ratio dan Total Assets Turn Over mengalami kenaikan maka akan diikuti dengan meningkatnya laba bersih yang dihasilkan oleh perusahaan. Dengan demikian maka akan dapat menarik perhatian suatu perusahaan karena dengan Return On Equity.

4. Koefisien Determinasi

Berdasarkan uji determinasi, besarnya nilai pengaruh variabel ditunjukan oleh $\mathrm{R}$ Square $=0,614$ maka $(\mathrm{KD}=\mathrm{r} 2 \times 100 \%=0,614 \times 100 \%=61,4 \%)$ jadi dapat disimpulkan bahwa Current Ratio (CR) dan Total Assets Turn Over (TATO) berpengaruh sebesar $61,4 \%$ terhadap Return On Equity (ROE), sedangkan sisanya 38,6\% dipengaruhi oleh variabel lain yang tidak diteliti didalam penelitian ini.

\section{PENUTUP}

\section{Kesimpulan}

Penelitian ini dilakukan untuk mengetahui pengaruh Current Ratio (CR) dan Total Assets Turn Over (TATO) terhadap Return On Equity (ROE) pada PT. Pertamina (Persero) periode 2010 - 2019. Berikut adalah beberapa kesimpulan yang dapat diberikan berdasarkan hasil analisis data penelitian:

1. Berdasarkan uji parsial (uji t) variabel Current Ratio (X1) tidak berpengaruh signifikan terhadap variabel Return On Equity (Y). Variabel Total Assets Turn
Over (X2) secara parsial mempengaruhi variabel Return On Equity (Y).

2. Berdasarkan uji simultan (uji f) menunjukan bahwa Current Ratio (X1) dan Total Assets Turn Over (X2) secara bersama - sama berpengaruh terhadap Return On Equity (Y).

3. Berdasarkan uji determinasi nilai $R$ Square sebesar 0,614 tau 61,4\%. Artinya peranan dari Current Ratio dan Total Assets Turn Over mempengaruhi Return On Equity sebesar $61,4 \%$ dan sisanya $38,6 \%$ dijelaskan oleh variabel lain yan tidak diteliti atau dibahas dalam penelitian ini.

\section{Saran}

Dari hasil kesimpulan dalam penelitian ini, maka saran yang dapat diberikan adalah sebagai berikut:

1. Pada rasio keuangan Current Ratio (CR) perusahaan diharapkan mampu menjaga keseimbangan agar tetap terjaga sesuai dengan tujuan perusahaan. Perusahaan juga harus menjaga sistemnya agar Current Ratio (CR) dapat ditekan, karena apabila Current Ratio (CR) menurun maka berpengaruh untuk menurunnya profitablitas perusahaan karena hal ini dapat mengganggu kestabilan perusahaan.

2. Pada rasio keuangan Total Assets Turn Over (TATO) perusahaan diharapkan tetap mampu menjaga keseimbangan agar tetap terjaga sesuai dengan tujuan perusahaan. Perusahaan harus menjaga sistemnya agar Total Assets Turn Over (TATO) dapat ditekan, karena apabila Total Assets Turn Over (TATO) meningkat maka semakin baik pengaruhnya terhadap profitabilitas perusahaan tersebut karena hal ini dapat meningkatnya aset perusahaan.

3. Pada rasio keuangan Return On Equity (ROE) perusahaan diharapkan tetap mampu dan stabil dalam menjaga kseimbangan antara laba bersih dan modal perusahaan agar tujuan perusahaan dapat tercapai. Diharapkan juga kepada perusahaan untuk menjaga 
agar Return On Equity (ROE) dapat terus meningkat setiap tahunnya.

\section{DAFTAR PUSTAKA}

Afandi, Pandi. (2018). Manajemen Sumber Daya Manusia Teori, konsep dan indikator. Jakarta: Zanafa.

Andri dan Endang. (2015). Pengantar Manajemen 3 in 1. Surakarta: Media Tera.

Arkunto, Suharsimi. (2016). Prosedur Penelitian Suatu Pendekatan Praktik, Jakarta: Rineka Cipta.

Brighman dan Houston. (2010). Dasar-dasar Manajemen Keuangan Buku I (edisi II). Jakarta: Salemba Empat.

Darminto, Prastowo. (2015). Analisis Laporan Keuangan, Konsep Aplikasi, Edisi ke empat. Yogyakarta: UPP STIM YKPN.

Fahmi, Irham. (2016). Aplikasi Analisis Laporan Keuangan. Bandung: Alfabeta.

Fahmi, Irham. (2016). Pengantar Manajemen Keuangan. Bandung: Alfabeta.

Fahmi, Irham. (2017). Analisis Laporan Keuangan. Bandung: Alfabeta.

Ghozali, Imam. (2016). Aplikasi Analisis Multivariete dengan program SPSS, Edisi keempat. Semarang: Badan Penerbit Universitas Diponegoro.

Hanafi. (2016). Manajemen Keuangan, Edisi dua. Yogyakarta: BPFE Yogyakarta.

Harahap. S. Safri. (2015). Analisis Kritis atas Laporan Keuangan, Edisi 1-10. Jakarta: Rajawali Persada.

Hasibuan, Melayu S.P, (2012). Manajemen Sumber Daya Manusia. Jakarta: PT. Bumi Aksara.

Herry. (2016). Analisis Laporan Keuangan. Jakarta: Gramedia Widiasarana Indonesia

Kasmir. (2015). Analisis Laporan Keuangan. Jakarta: Edisi Pertama, Rajawali Persada.

Kasmir. (2015). P.M.K \& Lainnya, L. K. Jakarta: Kencana Pranada Media Group.
Kasmir. (2016). Analisis Laporan Keuangan. jakarta: PT. Raja Grofindo Persada.

Kasmir. (2018). Analisis Laporan Keuangan. Jakarta: Rajawali Persada.

Lutfi, A. M., et al. (2021). Pengaruh Capital Adequacy Ratio Dan Bopo Ratio Terhadap Return On Asset Pada Pt. Bank Muamalat Indonesia, Tbk Periode 2010-2019. Jurnal Ekonomi Efektif, 3(3), 420-428.

Lutfi, A. M., et al. (2021). Pengaruh Capital Adequacy Ratio Dan Bopo Ratio Terhadap Return On Asset Pada Pt. Bank Muamalat Indonesia, Tbk Periode 2010-2019. Jurnal Ekonomi Efektif, 3(3), 420-428.

Munawir. (2016). Analisa Laporan Keuangan. Yogyakarta: Liberty Yogyakarta.

Musthafa. (2017). Manajmenen Keuangan, Edisi satu. Jakarta : Andi Publisher.

Najibullah, N., \& Nurjaya, N. (2021). Pengaruh non Performing Financing dan Financing to Deposit Ratio terhadap Pembiayaan pada Bank DKI Syariah. Jurnal Neraca Peradaban, 1(1), 48-55.

Najibullah, N., \& Nurjaya, N. (2021). Pengaruh non Performing Financing dan Financing to Deposit Ratio terhadap Pembiayaan pada Bank DKI Syariah. Jurnal Neraca Peradaban, 1(1), 48-55.

Priyatno, Duwi. (2017). Panduan Praktis Olah Data menggunakan SPSS.Edisi satu. Yogyakarta: Andi.

Subramanyam, K. R. (2017). Analisis Laporan Keuangan. Financial Statement Analysis, Edisi 11. Buku Satu. Jakarta: Salemba Empat.

Sugiyono. (2015). Metode Penelitian Kombinasi (Mix. Method). Bandung: Alfabeta.

Sugiyono. (2016). Metode Penelitian, Kuantitatif, Kualitatif dan R\&D. Bandung: Alfabeta, CV.

Terry,George R. Dalam Afifudin. (2016). Dasar-dasar Manajemen, (Terje: G.A Ticoalu). Bandung: Bumi Aksara. 